\section{Down to the very last drop}

Rehovot

DESPITE having the most comprehensive water-planning system in the world and a plethora of internationally recognized water experts, Israel is now suffering the worst water shortage in its history. Government officials blame three years of drought, but most scientists blame the officials.

Dr Gerald Stanhill, an agricultural meteorologist at the Ministry of Agriculture's Volcani Centre, says that, statistically, the past three years were not exceptionally dry. Indeed, they fell well within the rainfall values to be expected from the pattern of the past 55 years. Over that period, annual rainfall within the geographical boundaries of Mandatory Palestine (the area controlled by Israel today) averaged eight cubic kilometres, with a standard deviation of 25 per cent. Perhaps, as the cloud seeders claim, seeding operations have somewhat increased rainfall since the late 1960s. However, the statistics certainly show that rainfall has not declined.

"Israel's water crisis is like its money crisis. It has simply drawn more out of its account than has gone into it", Stanhill says. He welcomes the government's decision to cut back water consumption by 10 per cent this year, although he thinks that what is needed is a policy to build up and maintain a national water reserve at a level equal to three years' consumption.

Dr Joseph Shalheveth, acting director of the Volcani Centre and chief scientist at the Ministry of Agriculture, is less alarmed by developments than other scientists. In his view, "the situation is tight but not impossible". If next winter is also dry, however, drastic cutbacks will be required, as they were, he points out, in California seven years ago. In that case, Israel, for some years a net exporter of agricultural products, would become an importer.

Meanwhile, Volcani scientists who are largely responsible for the exceptionally efficient use of water in Israel's agriculture, are looking for new ways of getting more dollars out of every drop. They have successfully introduced mangoes, avocados, spices, medicinal plants and new varieties of flowers. But each has only a limited export market, and all of them together cannot possibly replace waterhungry cotton, now the main cash crop of Israeli farmers.

Nevertheless, cotton acreage is being reduced this year, as an emergency measure by one-third, and some water experts - who point out that it has been grown at a loss in recent seasons - say it should be eliminated completely, even if this clashes with the Zionist dream and bounced back.

drives thousands of farmers off the land.

Agriculturalists and their supporters are unwilling to write off cotton, pointing out that flowers, export earnings from which went up this year from $\$ 74$ million to $\$ 104$ million, were cultivated at a loss for some time and have now

Advocates of cotton point out that it can be irrigated with sewage water, but this

could be potentially dangerous, says Weizmann Institute Professor Mordeckai Magaritz and Daniel Ronen of the Israel Hydrological Service. Irrigation with treated sewage introduces undesirable amounts of pollutants into the soil, and unless comprehensive preventive measures are taken, into the aquifer as well. Magaritz and Ronen would therefore limit the irrigation of cotton with treated sewage to areas such as the semi-arid Negev, where there is practically no danger of polluting important aquifers.

Nechemia Meyers

\title{
Fossil bird shakes evolutionary hypotheses
}

\section{Washington}

Fossil remains claimed to be of two crowsized birds 75 million years older than Archaeopteryx have been found in the $\mathbf{2 2 5}$ million-year old Dockum Formation near Post, Texas. Sankar Chatterjee, a palaeontologist at Texas Tech University, who found the fossils, says they have advanced avian features that place them closer to the ancestor of modern birds than Archaeopteryx and make them possible direct ancestors.

Chatterjee intends to assign the find to a new genus, Protoavis. Among the features that Chatterjee claims identify Protoavis as a bird are elongated forelimbs, temporal fossae confluent with the eye socket, a definite furcula (wishbone), and a plate-like sternum (breastbone) with a small keel. The quadrate is also said to be typically avian. Other avian features are a cnemial crest on the tibia and flight-muscle attachment sites on the humerus. No feather impressions have been found, but Chatterjee claims to see quill nodes on the ulna and hand bones and he believes that Protoavis could fly. Protoavis also has reptilian features: four teeth in the forward part of its jaw, a tail and clawed fingers.

Protoavis seems certain to reopen a longrunning controversy on the evolution of birds, in particular whether the common ancestor of birds and dinosaurs was itself a

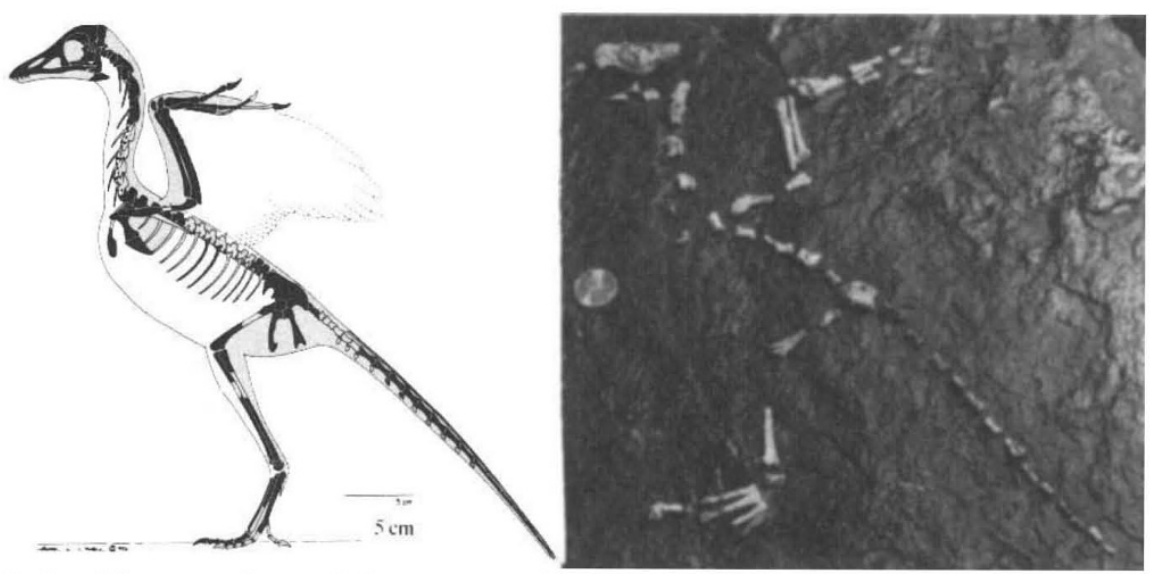

The fossil bones and an artist's reconstruction showing the recovered fossils (dark bones) of the putative Protoavis "bird".

dinosaur. Protoavis, from the late Triassic, appears at the time of the earliest dinosaurs, and if the identification is upheld it seems likely that it will be used to argue against the view of John Ostrom of Yale University that birds are descended from the dinosaurs. It also tends to confirm what many palaeontologists have long suspected, that Archaeopteryx is not on the direct line to modern birds. It is in some ways more reptilian than Protoavis, and the period between the late Jurassic Archaeopteryx and the worldwide radiation of birds in the Cretaceous has to some seemed suspiciously brief.

Chatterjee's research has for the past six years been supported by the National Geographic Society, which publicized the find last week. The work has yet to be published in a peer-reviewed journal, but two independent palaeontologists (including Ostrom) who have examined Protoavis agree it should probably be classified as a bird. Ostrom stresses, however, that the remains are very fragmentary, and while agreeing with Chatterjee's tentative classification says the case is not finally proven. But Ostrom disagrees with Chatterjee in not seéing even indirect evidence of feathers, saying the bones where quill nodes might be seen are badly preserved, nor does he consider the forelimbs especially elongated. Tim Beardsley 